\title{
PAPER
}

Cite this: Dalton Trans., 2013, 42, 7755

Received 28th November 2012, Accepted 11th March 2013

DOI: $10.1039 / \mathrm{c} 3 \mathrm{dt} 32859 \mathrm{~g}$

www.rsc.org/dalton

\section{Structures of polynuclear complexes of palladium(II) and platinum(II) formed by slow hydrolysis in acidic aqueous solution $\dagger$}

\author{
Natallia Torapava, ${ }^{a}$ Lars I. Elding, ${ }^{\mathrm{b}}$ Hugo Mändar, ${ }^{\mathrm{c}} \mathrm{Kaspar}^{\mathrm{R}}$ Roosalu ${ }^{\mathrm{c}}$ and \\ Ingmar Persson ${ }^{* a}$
}

\begin{abstract}
The aqua ions of palladium(॥) and platinum(॥) undergo extremely slow hydrolysis in strongly acidic aqueous solution, resulting in polynuclear complexes. The size and structures of these species have been determined by EXAFS and small angle X-ray scattering, SAXS. For palladium(॥), the EXAFS data show that the $\mathrm{Pd}-\mathrm{O}$ and $\mathrm{Pd}$...Pd distances are identical to those of crystalline palladium(॥) oxide, but the intensities of the $\mathrm{Pd}$...Pd distances in the Fourier transform at 3.04 and $3.42 \AA$ are significantly lower compared to those of crystalline PdO. Furthermore, no Pd...Pd distances beyond $4 \AA$ are observed. These observations strongly indicate that the polynuclear palladium(II) complexes are oxido- and hydroxido-bridged species with the same core structure as solid palladium(॥) oxide. Based on the number of Pd...Pd distances, as derived from the EXAFS data, their size can be estimated to be approximately two unit cells, or ca. $1.0 \mathrm{~nm}^{3}$. For platinum(॥), EXAFS data of the polynuclear species formed in the slow hydrolysis process show Pt-O and Pt...Pt distances identical to those of amorphous platinum(॥) oxide, precipitating from the solution studied. The Pt...Pt distances are somewhat different from those reported for crystalline platinum(॥) oxide. The polynuclear platinum(॥) complexes have a similar structure to the palladium ones, but they are somewhat larger, with an estimated diameter of 1.5-3.0 $\mathrm{nm}$. It has not been possible to precipitate any of these species by ultracentrifugation. They are detectable by SAXS, indicating diameters between 0.7 and $2 \mathrm{~nm}$, in excellent agreement with the EXAFS observations. The number of oxido- relative to hydroxido bridges will increase with increasing size of the complex. The charge of the complexes will remain about the same, +4 , at growth, with approximate formulas $\left[\mathrm{Pd}_{10} \mathrm{O}_{4}(\mathrm{OH})_{8}\left(\mathrm{H}_{2} \mathrm{O}\right)_{12}\right]^{4+}$ and $\left[\mathrm{Pt}_{14} \mathrm{O}_{8}(\mathrm{OH})_{8}\left(\mathrm{H}_{2} \mathrm{O}\right)_{12}\right]^{4+}$ for complexes with a size of 2 and 3 unit cells of the corresponding solid metal oxide, respectively. Their high ionic charge in acidic aqueous solution will result in a stabilizing hydration shell.
\end{abstract}

\section{Introduction}

Since their synthesis and characterization in the late 1960s and $1970 \mathrm{~s}^{1-4}$ the $\mathrm{d}^{8}$ tetraaqua cations of palladium(II) and platinum (II) have been the subject of continuous interest. Water exchange kinetics $^{5-8}$ substitution behavior ${ }^{1,9}$ and electronic spectra ${ }^{10}$ have been studied and DFT calculations on the water exchange mechanisms of $\mathrm{Pt}\left(\mathrm{H}_{2} \mathrm{O}\right)_{4}{ }^{2+}$ and $\mathrm{Pd}\left(\mathrm{H}_{2} \mathrm{O}\right)_{4}{ }^{2+}$ have been reported. ${ }^{11}$ No solid state structures containing these hydrated metal ions have been described so far. The nearest approximation is the crystal structure of $\mathrm{K}_{2}\left[\mathrm{Pt}\left(\mathrm{NO}_{3}\right)_{4}\right] \cdot 1 / 2 \mathrm{H}_{2} \mathrm{O}$ and the

\footnotetext{
${ }^{a}$ Department of Chemistry, Swedish University of Agricultural Sciences, P.O. Box 7015, SE-750 07 Uppsala, Sweden.E-mail: ingmar.persson@slu.se ${ }^{b}$ Department of Chemistry, Lund University, P.O. Box 124, SE-221 00 Lund, Sweden ${ }^{c}$ Institute of Physics, University of Tartu, 4 Tähe Str., EST-51010 Tartu, Estonia †Electronic supplementary information (ESI) available. See DOI: 10.1039/c3dt32859g
}

corresponding palladium compound, displaying square-planar co-ordination with metal-oxygen distances of 2.010 and $2.000 \AA$, respectively, without any explicit axial interactions. $^{12,13}$ Substitution reactions of square-planar $\mathrm{d}^{8}$ metal complexes are usually associatively activated, forming fivecoordinate transition states, including the entering ligand. ${ }^{14}$ In this context the role of the empty $d_{z^{2}}$ orbital of the metal ion and axial interactions is fundamental. Early Pt-NMR, LAXS, EXAFS and XANES studies gave no evidence for such axial co-ordination. ${ }^{5,15,16}$ More recently, however, theoretical QM/MM MD and Car-Parinello simulations as well as EXAFS and vibrational spectroscopy data ${ }^{17-28}$ indicate a more or less well-ordered hydration structure on both sides of the co-ordination plane, with a possible strongly tetragonally distorted octahedral co-ordination, with four in-plane water molecules bound with short $\mathrm{Pd} / \mathrm{Pt}-\mathrm{O}$ distances at $2.00 \AA$ and one or two additional ones, loosely bound axially at 2.7-2.85 ̊.. $21,27,28$ 
The $\mathrm{p} K_{\mathrm{a} 1}$ values of the aqua ions of palladium(II) and platinum(II) are 3.0 and $>2.5$, respectively. ${ }^{3,29}$ In order to avoid hydrolysis and formation of hydroxido complexes and polynuclear species, experimental studies on the aqua ions have to be performed in a strongly acidic medium by use of freshly prepared solutions. At higher $\mathrm{pH}$, the formation of hydroxido complexes has been studied. ${ }^{30-35}$ Mononuclear hydroxido complexes up to $\mathrm{Pd}(\mathrm{OH})_{4}{ }^{2-}$ and $\mathrm{Pt}(\mathrm{OH})_{4}{ }^{2-}$ as well as polynuclear ones like $\mathrm{Pd}_{2}(\mathrm{OH})_{2}{ }^{2+}$ and $\mathrm{Pd}_{4}(\mathrm{OH})_{4}{ }^{4+}$ have been identified in solution. ${ }^{30-34}$ Palladium(II) hydrolysis and hydroxido complexes may play an important role in natural water. ${ }^{35-39}$

An EXAFS study of the hydrolysis of palladium(II) in alkaline aqueous solution has indicated two $\mathrm{Pd} \cdots \mathrm{Pd}$ distances, one at $2.65 \AA$ (via a double oxygen bridge) and another at $3.2 \AA$ (via a single oxygen bridge). ${ }^{40}$ It was proposed that polynuclear hydroxido complexes of palladium(II) have a chain structure, where each chain fragment contains about $100 \mathrm{Pd}$ atoms, and where $\mathrm{PdO}_{4}$ squares are linked by one or two bridging oxygens. Aging of such solutions was proposed to lead to size reduction of these polynuclear complexes. Solid-state structures of hydroxido- or oxido-bridged di-, triand tetrameric platinum compounds were determined early, displaying Pt-O distances between 1.99 and $2.08 \AA$ depending on the structure. ${ }^{41-43}$

Even in strongly acidic aqueous solution it cannot be excluded that the aqua ions of palladium(II) and platinum(II) form polynuclear hydrolysis complexes very slowly, most probably initiated by formation of minute concentrations of hydroxido complexes. In the present work the structures of the hydrolysis products formed in $1 \mathrm{~mol} \mathrm{dm}{ }^{-3}$ perchloric acid solutions of the aqua ions stored for $c a .15$ years under nitrogen in darkness at $c a .4{ }^{\circ} \mathrm{C}$ have been studied by use of EXAFS and small angle X-ray scattering (SAXS).

\section{Experimental}

\section{Chemicals and solutions}

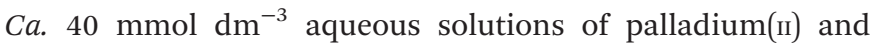
platinum(II) perchlorate in $1.0 \mathrm{~mol} \mathrm{dm}^{-3}$ perchloric acid were prepared as described elsewhere., ${ }^{3,4}$ These solutions were stored for a prolonged period of time ( $c a .15$ years) in closed flasks protected from light at $c a .4{ }^{\circ} \mathrm{C}$ under nitrogen. The palladium(II) solution is dark brown with no sign of precipitates. The platinum(II) solution is yellow-light brown with minor amounts of a light brown precipitate of amorphous platinum(II) oxide (vide infra). Palladium(II) oxide, PdO (Aldrich, 99.995\%), was used as purchased. Platinum(II) oxide, PtO, was filtered off the platinum(II) perchlorate solution as a very fine light brown powder. X-ray powder diffraction, using MoK $\alpha$ radiation, $\lambda=0.71073 \AA$, showed that this phase has a low degree of crystallinity with only one well-defined diffraction peak which fits well with crystalline platinum(II) oxide, Fig. 1. The obtained structural parameters of this mainly amorphous platinum(II) oxide are slightly different from those previously reported for crystalline PtO (vide infra). ${ }^{44,51}$

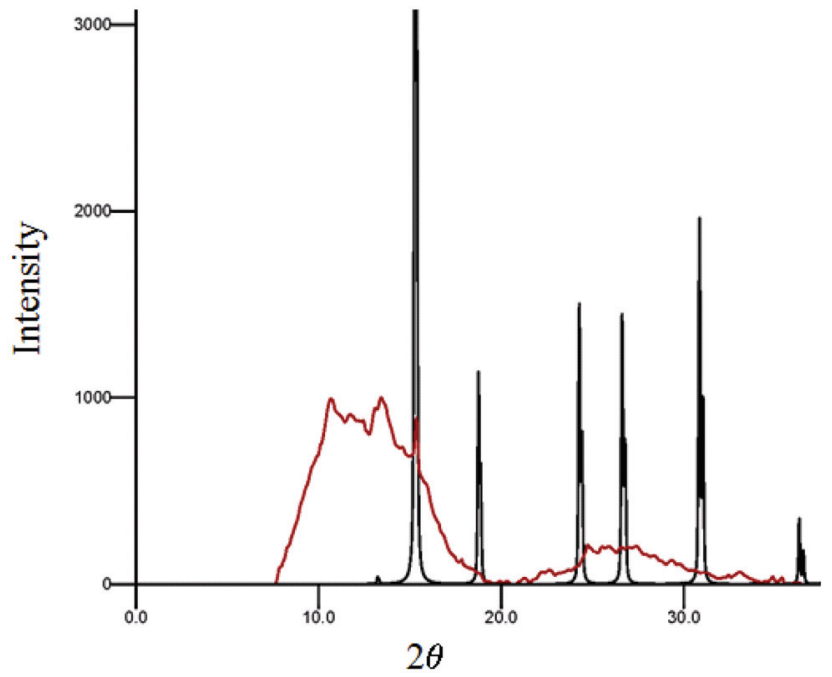

Fig. 1 XRD pattern, using MoK $\alpha$ radiation, $\lambda=0.71073 \AA$, for polycrystalline PtO calculated from the structure parameters reported by ref. 44 using EVA (ref. 45), in black and the precipitate formed in an acidic aqueous solution of $\mathrm{Pt}\left(\mathrm{H}_{2} \mathrm{O}\right)_{4}{ }^{2+}$ after several years of storage, in red.

\section{EXAFS - data collection}

EXAFS measurements on crystalline palladium(II) oxide, the mainly amorphous platinum(II) oxide, and the acidic aqueous solutions of the palladium(II) and platinum(II) hydrolysis products were performed at the Pd $K$ and Pt $L_{3}$ X-ray absorption edges. Data were collected at the wiggler beam line 4-1 at the Stanford Synchrotron Radiation Lightsource (SSRL), Stanford, USA, operating at $3.0 \mathrm{GeV}$ and 297-300 mA (top-up mode). The EXAFS station was equipped with a $\mathrm{Si}[220]$ double crystal monochromator. Higher order harmonics were reduced by detuning the second monochromator crystal to reflect 60 and $50 \%$ of maximum intensity at the end of the scans for palladium and platinum, respectively. Internal energy calibration was made with palladium and platinum metal foils assigned to $24350 \mathrm{eV}$ (Pd $K$ edge) and $11654 \mathrm{eV}$ (Pt $L_{3}$ edge). ${ }^{46}$ All measurements were performed in transmission mode. For the solid samples 3-4 scans and for the solutions 6-10 scans were averaged after energy calibration by means of the EXAFSPAK program package. ${ }^{47}$

\section{EXAFS - data analysis}

The EXAFSPAK program package was used for data treatment. The standard deviations reported for the refined parameters were obtained from $k^{3}$ weighted least squares refinements of the EXAFS function $\chi(k)$, and do not include systematic errors. These statistical error values allowed reasonable comparisons, e.g. of the significance of relative shifts in the distances. However, the variations in the refined parameters, including the shift in the $E_{\mathrm{o}}$ value (with $k=0$ ), using different models and data ranges, indicated that the absolute accuracy of the distances is within \pm 0.005 to $0.02 \AA$ for well-defined interactions. The "standard deviations" have been increased accordingly to include estimated additional systematic errors. 


\section{Small angle X-ray scattering}

SAXS data for the acidic aqueous solutions of hydrolyzed palladium(II) and platinum(II) were recorded in the range $0.005-0.60 \AA^{-1}$ of the scattering vector modulus $(q)$ by use of a materials research diffractometer SmartLab (Rigaku ${ }^{\mathrm{TM}}$ ) (camera radius $300 \mathrm{~mm}$ ) operating with $\mathrm{CuK} \alpha$-radiation $(\lambda=1.5418 \AA)$. Samples were sealed into $1.0 \mathrm{~mm}$ diameter fused ends Mark capillaries (Hilgenberg $\mathrm{GmbH}$ ). An advanced version of the program AXES $^{48}$ was used for data smoothing and background correction, taking into account camera and electrolyte scattering. The program NanoSolver (Rigaku ${ }^{\mathrm{TM}}$ ) was used for fitting of SAXS patterns and refinement of particle sizes.

\section{Ultracentrifugation}

The palladium and platinum solutions were centrifuged for $30 \mathrm{~min}$ at $18000 \mathrm{rpm}$ (47 900g) using a Beckman J2-HS centrifuge with a JA-18 rotor. No visible precipitation was observed.

\section{Results and discussion}

The EXAFS data for the palladium(II) and platinum(II) hydrolysis products studied show that the obtained $\mathrm{M} \cdots \mathrm{M}$ and $\mathrm{M}-\mathrm{O}$ distances are almost identical to those of the corresponding solid oxides, even though the number of $\mathbf{M} \cdots \mathbf{M}$ distances is significantly lower for the hydrolyzed species than the oxides. In addition, no distances are found beyond 4-5 ̊, $c f$. Fig. 2 and 3.
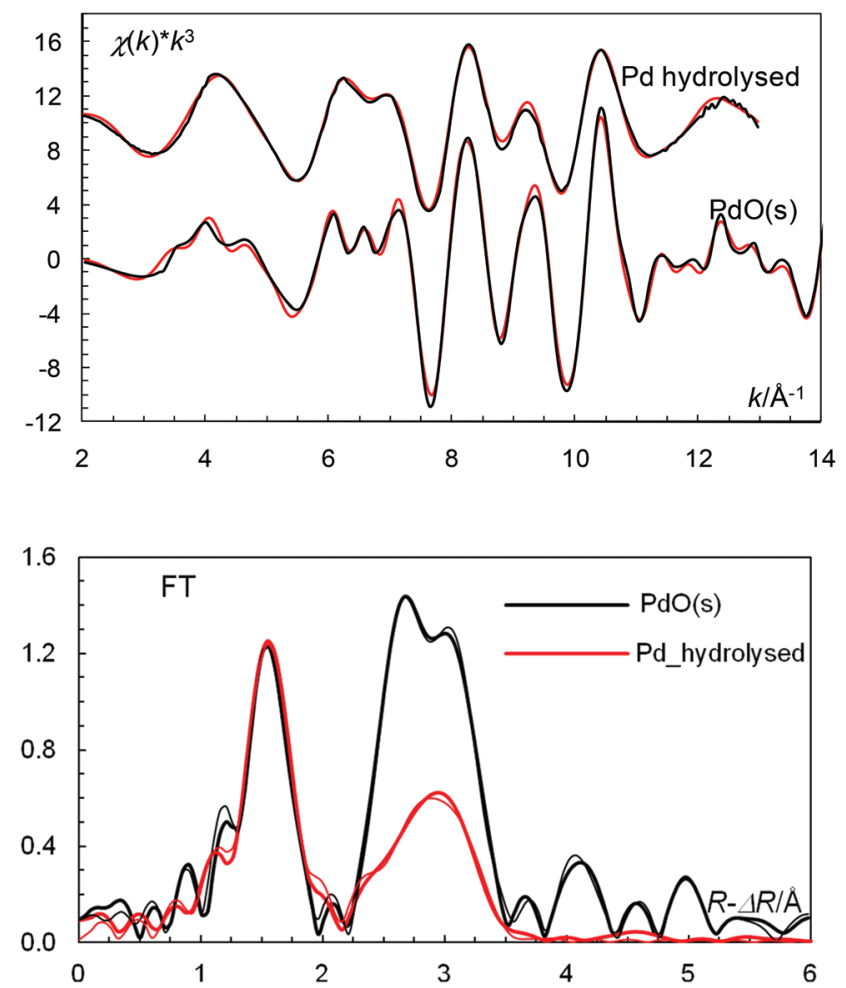

Fig. 2 (Top) Fit of Pd $K$ edge EXAFS data and (bottom) its respective Fourier transform for a hydrolyzed palladium(॥) perchlorate solution, thin black curve experimental, red curve-model.
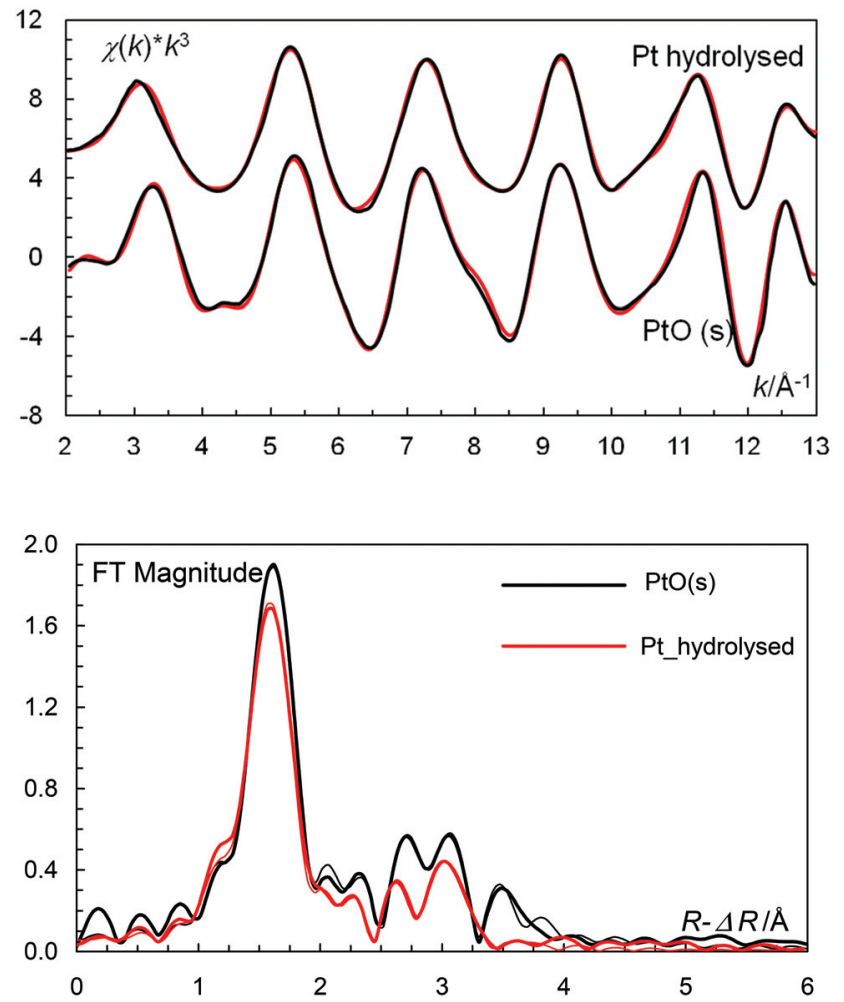

Fig. 3 (Top) Fit of Pt $L_{3}$ edge EXAFS data and (bottom) its respective Fourier transform for solid platinum(॥) oxide, thin black curve - experimental, red curve-model.

The number of $\mathrm{M}-\mathrm{O}$ bond distances is equal to four, strongly indicating that the terminal palladium(II) and platinum(II) ions in the hydrolysis products bind water molecules, hydroxide or oxide groups at the same distances as observed in the solid oxides $^{44,49-51}$ and the hydrated ions, ${ }^{21,27,28}$ in order to complete a square-planar coordination geometry. These observations strongly indicate that the hydrolyzed palladium(II) and platinum(II) species are present as well defined small clusters or polynuclear complexes, with the same core structure as the solid oxides.

In these refinements, it was assumed that the Debye-Waller factor was similar for the palladium(II) hydrolysis complex as for the crystalline phase, and that the hydrolysis complex of platinum(II) has a similar Debye-Waller factor to the solid amorphous phase. As the Debye-Waller coefficient and the number of distances are strongly correlated, they were not refined simultaneously. The Debye-Waller coefficients obtained in the refinements of the structural parameters of the solid oxides with a fixed number of distances were used to refine the number of $\mathbf{M} \cdots \mathbf{M}$ distances in the hydrolysis species.

The structure of crystalline palladium(II) oxide at normal temperature and pressure has been reported three times with very similar results. ${ }^{4,49-51}$ Another three palladium(II) oxide structures have been reported. However, one of these was recorded at high pressure, and another as a supported film. ${ }^{52-54}$ The $\mathrm{Pd}-\mathrm{O}$ and $\mathrm{Pd} \cdot \mathrm{Pd}$ Pdistances obtained from our EXAFS data for solid palladium(II) oxide are in close agreement 
Table 1 Number of distances, $N$, mean bond distances, $d / \AA$, and Debye-Waller coefficients, $\sigma^{2} / \AA^{2}$, in the EXAFS studies of solid PdO and hydrolyzed palladium(॥) perchlorate solutions at room temperature. The data for $\mathrm{PdO}(\mathrm{s})$ are taken from McBride et al. ${ }^{50}$

\begin{tabular}{|c|c|c|c|c|c|}
\hline Species & Interaction & $N$ & $d$ & $\sigma^{2}$ & $\begin{array}{l}d \text { (Single } \\
\text { crystal) }\end{array}$ \\
\hline \multirow[t]{12}{*}{$\operatorname{PdO}(s)^{50}$} & Pd-O & 4 & $2.021(3)$ & $0.0022(3)$ & 2.019 \\
\hline & $\mathrm{Pd} \cdots \mathrm{Pd}$ & 4 & $3.060(3)$ & $0.0045(4)$ & 3.036 \\
\hline & $\mathrm{Pd} \cdots \mathrm{Pd}$ & 8 & $3.452(5)$ & $0.0055(5)$ & 3.421 \\
\hline & $\mathrm{Pd} \cdots \mathrm{Pd}$ & 4 & $4.29(2)$ & $0.006(3)$ & 4.294 \\
\hline & $\mathrm{Pd} \cdots \mathrm{Pd}$ & 16 & $5.363(6)$ & $0.010(2)$ & $\begin{array}{l}5.324+ \\
5.490\end{array}$ \\
\hline & $\mathrm{Pd} \cdots \mathrm{Pd}$ & 12 & $6.15(2)$ & $0.013(2)$ & $\begin{array}{l}6.072+ \\
6.131\end{array}$ \\
\hline & $\mathrm{Pd} \cdots \mathrm{Pd}$ & 24 & $6.96(2)$ & $0.013(2)$ & $\begin{array}{l}6.789+ \\
6.842+ \\
6.969\end{array}$ \\
\hline & $\mathrm{Pd} \cdots \mathrm{O}$ & 8 & $3.766(12)$ & $0.0032(15)$ & 3.646 \\
\hline & $\mathrm{Pd} \cdots \mathrm{O}$ & 4 & $4.24(2)$ & $0.005(2)$ & 4.274 \\
\hline & $\mathrm{Pd} \cdots \mathrm{O}$ & 4 & $4.82(2)$ & $0.007(3)$ & 4.745 \\
\hline & $\mathrm{Pd} \cdots \mathrm{O}$ & 8 & $5.26(2)$ & $0.006(3)$ & 5.242 \\
\hline & $\mathrm{Pd} \cdots \mathrm{O}$ & 8 & $5.643(10)$ & $0.005(2)$ & 5.633 \\
\hline \multirow[t]{3}{*}{ Hydr. $\mathrm{Pd}^{2+}$} & Pd-O & 4 & $1.999(2)$ & $0.0026(2)$ & \\
\hline & $\mathrm{Pd} \cdots \mathrm{Pd}$ & $1.7(1)$ & $3.020(3)$ & 0.0045 & \\
\hline & Pd $\cdots P d$ & $2.4(2)$ & $3.407(4)$ & 0.0055 & \\
\hline
\end{tabular}

with those reported in the literature, but with a slight tendency of somewhat longer distances (Table 1). The number of Pd...Pd distances for the hydrolysis product given in Table 1 corresponds to polynuclear complexes with a size of $c a$. two unit cells of palladium(II) oxide grown along the $a$ or $b$ axis, including water molecules in the terminal binding positions, giving a size of about $11 \times 11 \times 9 \AA^{3}\left(c a .1 .0 \mathrm{~nm}^{3}\right)$. The number of $\mathrm{M} \cdots \mathrm{M}$ distances also shows that the complexes do not grow along the $c$ axis, as this would give a significantly different ratio of the number of $\mathrm{M} \cdots \mathrm{M}$ distances than observed, $c f$. Table S1. $†$ The $\mathrm{pH}$ in an aqueous suspension of palladium(II) oxide was determined to be 3.60 , strongly indicating a value of $\mathrm{pH}_{\mathrm{PZC}}$ in the region 3-4. This is supported by a zeta potential study, where $\mathrm{pH}_{\mathrm{PZC}}$ is reported to be 5.1 at $235{ }^{\circ} \mathrm{C}$ and $<2$ at $23{ }^{\circ} \mathrm{C} .{ }^{55}$ However, the latter value is questionable, since palladium(II) oxide easily reduces in the presence of hydrogen at low $\mathrm{pH}$. The observed $\mathrm{pH}_{\mathrm{PzC}}$ value of 3-4 indicates that the surfaces of the oxido- and hydroxido-bridged palladium(II) hydrolysis complexes will be positively charged at $\mathrm{pH} 0$. Complexes with dimensions similar to two unit cells of solid palladium(II) oxide grown along the $a$ or $b$ axis would have the composition $\left[\mathrm{Pd}_{10} \mathrm{O}_{4}(\mathrm{OH})_{8}\left(\mathrm{H}_{2} \mathrm{O}\right)_{12}\right]^{4+}$, see Fig. 4a. The significant ionic charge of these complexes in acidic aqueous solution would result in a well-defined hydration shell, explaining their high stability in aqueous solution.

The Pt-O and Pt...Pt distances obtained from the EXAFS data for amorphous platinum(II) oxide are significantly different from those reported in the literature for the crystalline phase ${ }^{44,51}$ However, the distances for the mainly amorphous platinum(II) oxide used in the present study and the hydrolyzed platinum(II) species are in very good agreement, $c f$. Table 2. It is of interest to note that the Debye-Waller coefficients of the $\mathrm{M} \cdots \mathrm{M}$ distances are larger for the oxide of platinum(II) than for
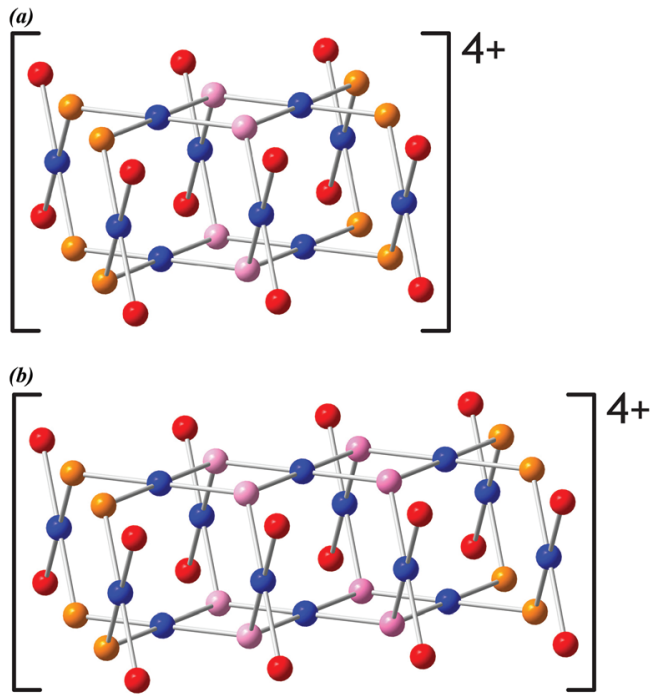

Fig. 4 (a) Proposed structure of a polynuclear oxido-hydroxido-bridged palladium(II) hydrolysis complex, $\left[\mathrm{Pd}_{10} \mathrm{O}_{4}(\mathrm{OH})_{8}\left(\mathrm{H}_{2} \mathrm{O}\right)_{12}\right]^{4+}$, slowly formed in acidic aqueous solution. (b) Corresponding structure for the platinum(॥) complex $\left[\mathrm{Pt}_{14} \mathrm{O}_{8}(\mathrm{OH})_{8}\left(\mathrm{H}_{2} \mathrm{O}\right)_{12}\right]^{4+}$. Blue atoms denote metal(II) ions, pink ones $\mu_{3}$-oxido bridging oxygens, and yellow-orange ones $\mu_{2}$-hydroxido bridging oxygens. The oxygens of terminal water molecules, marked in red, complete the squareplanar arrangement around the $\mu_{2}$-hydroxido bridged metal atoms. Due to the high ionic charge of these complexes in acidic aqueous solution, they are assumed to be well hydrated, thus being protected from aggregation and precipitation.

Table 2 Number of distances, $N$, mean bond distances, $d / \AA$, and Debye-Waller coefficients, $\sigma^{2} / \AA^{2}$, in the EXAFS studies of solid PtO and hydrolyzed platinum(॥) perchlorate solutions at room temperature. The data for $\mathrm{PtO}(\mathrm{s})$ are taken from Waser et al..$^{51}$

\begin{tabular}{|c|c|c|c|c|c|}
\hline Species & Interaction & $N$ & $d$ & $\sigma^{2}$ & $\begin{array}{l}d \text { (Single } \\
\text { crystal) }\end{array}$ \\
\hline \multirow[t]{4}{*}{$\mathrm{PtO}(\mathrm{s})^{51}$} & $\mathrm{Pt}-\mathrm{O}$ & 4 & $2.002(2)$ & $0.0019(2)$ & 2.019 \\
\hline & $\mathrm{Pt} \cdots \mathrm{Pt}$ & 4 & $3.101(3)$ & $0.0056(3)$ & 3.078 \\
\hline & $\mathrm{Pt} \cdots \mathrm{Pt}$ & 8 & $3.311(9)$ & $0.0114(9)$ & 3.445 \\
\hline & $\mathrm{Pt} \cdots \mathrm{O}$ & 8 & $3.782(9)$ & $0.0032(7)$ & 3.691 \\
\hline \multirow[t]{4}{*}{ Hydr. $\mathrm{Pt}^{2+}$} & $\mathrm{Pt}-\mathrm{O}$ & 4 & $2.004(2)$ & $0.0028(2)$ & \\
\hline & $\mathrm{Pt} \cdots \mathrm{Pt}$ & $2.3(3)$ & $3.094(3)$ & 0.0056 & \\
\hline & $\mathrm{Pt} \cdots \mathrm{Pt}$ & $5.1(3)$ & $3.299(5)$ & 0.0114 & \\
\hline & $\mathrm{Pt} \cdots \mathrm{Pt}$ & $5.1(3)$ & $3.299(5)$ & 0.0114 & \\
\hline
\end{tabular}

that of palladium(II), $c f$. Tables 1 and 2, supporting the expected larger distribution of Pt...Pt distances for a mainly amorphous platinum(II) oxide like the one studied here. The obtained number of Pt...Pt distances given in Table 2 corresponds to complexes with a size of $c a$. three unit cells of PtO grown along. the $a$ or $b$ axis, giving a diameter of 1.5-3.0 $\AA$, corresponding to a volume of $c a$. 1-2 $\mathrm{nm}^{3}$. A complex with a size corresponding to three units of solid platinum(II) oxide would have the formula $\left[\mathrm{Pt}_{14} \mathrm{O}_{8}(\mathrm{OH})_{8}\left(\mathrm{H}_{2} \mathrm{O}\right)_{12}\right]^{4+}$, again with a well-defined outer sphere hydration shell, $c f$. Fig. $4 \mathrm{~b}$.

In order to further estimate the cluster size, small angle X-ray scattering (SAXS) experiments were performed on the solutions studied by EXAFS, summarized in Fig. 5. The raw scattering data for the hydrolysis products were only slightly 

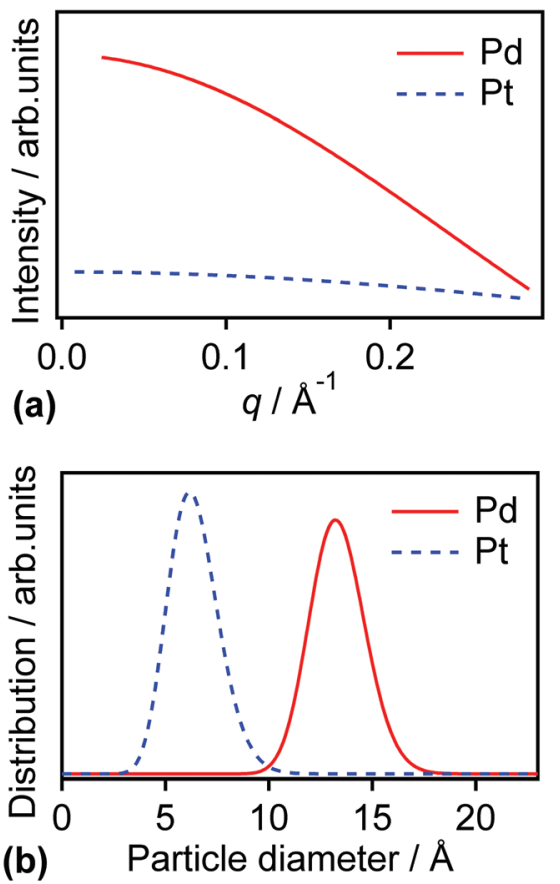

Fig. 5 Results from SAXS analysis: (a) scattering patterns (smoothed and corrected for buffer and transmission) and (b) size distribution functions, calculated by assuming spherical particles, for hydrolyzed palladium(॥) and platinum(॥) samples.

above the scattering pattern of the pure electrolyte, $1.0 \mathrm{~mol}$ $\mathrm{dm}^{-3}$ perchloric acid. The small difference is due to the low concentrations of the species studied, and to the relatively high absorption factor of the electrolyte. The transmission coefficients $(T)$ of the palladium(II) and platinum(II) compounds corrected for electrolyte scattering and absorption were 0.86 and 0.95 , respectively. The scattering signal from the polynuclear platinum(II) complex was only slightly above the noise level. After correction, the resulting scattering curve for the platinum(II) complex in Fig. 5a shows a small decrease in $q$. The mean particle diameter for the platinum(II) complex determined from the size distribution function (Fig. 5b) was about $0.7 \mathrm{~nm}$.

The palladium(II) oxide scattering pattern, on the other hand, shows a clear decay with increasing $q$ which can be explained by the presence of larger species at higher concentrations in the reference sample compared to the solution of a hydrolyzed platinum(II) complex. Depending on the fitting parameters of the model, the mean particle diameter of the hydrolyzed palladium(II) complex can be determined to be in the range of $0.8-2 \mathrm{~nm}$, whereas the most probable diameter remains around $1.3 \mathrm{~nm}$. Therefore, based on the SAXS results, it can be concluded that the hydrolysis products of palladium(II) as well as platinum(II) are very small species, with diameters around $0.7-2 \mathrm{~nm}$, being present in low concentrations, thus confirming qualitatively the EXAFS results. The concentrations, however, are too low to allow a more precise determination of the size and shape by SAXS.

\section{Conclusions}

The aqua ions of palladium(II) and platinum(II) hydrolyse in $1.0 \mathrm{~mol} \mathrm{dm} \mathrm{dm}^{-3}$ perchloric acid, forming polynuclear complexes with the same core structure as crystalline palladium(II) oxide and amorphous platinum(II) oxide, respectively, as determined by EXAFS. The rate of formation of these polynuclear species is very low. After ca. 15 years of storage, their size is $1-2 \mathrm{~nm}^{3}$. They are highly charged due to protonation of the terminal and surface oxygens as the $\mathrm{pH}$ of the studied solution is several $\mathrm{pH}$ units below the estimated $\mathrm{pH}_{\mathrm{PZC}}$. A reasonable structure would be oxido- and hydroxido-bridged complexes of the type $\left[\mathrm{M}_{n} \mathrm{O}_{(n-6)}(\mathrm{OH})_{8}\left(\mathrm{H}_{2} \mathrm{O}\right)_{12}\right]^{4+}, n=10$ for $\mathrm{Pd}$ and $n=14$ for $\mathrm{Pt}$, as depicted in Fig. 4. Surface-bound water molecules are assumed to complete the square-planar co-ordination geometry around the metal ions. Due to the high ionic charge of these complexes in acidic aqueous solution, they are expected to be strongly hydrated, which would protect them from aggregation and precipitation. They are too small to be ultracentrifuged, to give unambiguous X-ray diffraction patterns, or to be quantitatively characterized by SAXS.

\section{Acknowledgements}

We are grateful for financial support from the Swedish and Estonian Research Councils. Part of this research was carried out at the Stanford Synchrotron Radiation Lightsource, a national user facility operated by Stanford University on behalf of the U.S. Department of Energy, Office of Basic Energy Sciences. The SSRL Structural Molecular Biology Program is supported by the Department of Energy, Office of Biological and Environmental Research, and by the National Institutes of Health, National Center for Research Resources, Biomedical Technology Program. The SAXS analysis was supported by the Estonian Science Foundation (grant 7603) and by Estonian Centre of Excellence in Research Project TK117T. A referee is thanked for very valuable comments.

\section{References}

1 D. T. Richens, The Chemistry of Aqua Ions, Wiley, Chichester, 1997, pp. 499-508.

2 C. K. Jørgensen and L. Rasmussen, Acta Chem. Scand., 1968, 22, 2313-2323, and references therein.

3 L. I. Elding, Inorg. Chim. Acta, 1972, 6, 647-651.

4 L. I. Elding, Inorg. Chim. Acta, 1976, 20, 65-69.

5 Ö. Gröning, T. Drakenberg and L. I. Elding, Inorg. Chem., 1982, 21, 1820-1824.

6 L. Helm, L. I. Elding and A. E. Merbach, Helv. Chim. Acta, 1984, 67, 1453-1460.

7 L. Helm, L. I. Elding and A. E. Merbach, Inorg. Chem., 1985, 24, 1719-1721.

8 Ö. Gröning and L. I. Elding, Inorg. Chem., 1989, 28, 33663372. 
9 For instance: (a) L. I. Elding, Inorg. Chim. Acta, 1972, 6, 683-688; (b) L. I. Elding, Inorg. Chim. Acta, 1978, 28, 255262; (c) B. Hellquist, L. I. Elding and Y. Ducommun, Inorg. Chem., 1988, 27, 3620-3623; (d) T. Shi and L. I. Elding, Inorg. Chem., 1996, 35, 735-740; (e) T. Shi and L. I. Elding, Inorg. Chem., 1996, 35, 5941-5947.

10 L. I. Elding and L. F. Olsson, J. Phys. Chem., 1978, 82, 6974.

11 R. J. Deeth and L. I. Elding, Inorg. Chem., 1996, 35, 50195026.

12 L. I. Elding and Å. Oskarsson, Inorg. Chim. Acta, 1985, 103, 127-131.

13 L. I. Elding, B. Norén and Å. Oskarsson, Inorg. Chim. Acta, 1986, 114, 71-74.

14 M. L. Tobe and J. Burgess, Inorganic Reaction Mechanisms, Longman, 1999, pp. 70-112.

15 B. Hellquist, L. A. Bengtsson, B. Holmberg, B. Hedman, I. Persson and L. I. Elding, Acta Chem. Scand., 1991, 45, 449-455.

16 R. Ayala, E. Sanchez Marcos, S. Diaz-Moreno, V. A. Solé and A. Munoz-Paez, J. Phys. Chem. B, 2001, 105, 7588-7593.

17 J. M. Martinez, F. Torrico, R. R. Pappalardo and E. Sanchez Marcos, J. Phys. Chem. B, 2004, 108, 1585115855.

18 F. Torrico, R. R. Pappalardo, E. Sanchez Marcos and J. M. Martinez, Theor. Chem. Acc., 2006, 115, 196-203.

19 J. Purans, B. Fourest, B. Cannes, V. Sladkov, F. David, L. Venault and M. Lecomte, J. Phys. Chem. B, 2005, 109, 11074-11082.

20 S. A. Ali Shah, T. S. Hofer, M. Q. Fatmi, B. R. Randolf and B. M. Rode, Chem. Phys. Lett., 2006, 426, 301-305.

21 T. S. Hofer, B. R. Randolf, S. A. Ali Shah, B. M. Rode and I. Persson, Chem. Phys. Lett., 2007, 445, 193-197.

22 E. C. Beret, J. M. Martinez, R. R. Pappalardo, E. Sanchez Marcos, N. L. Doltsinis and D. Marx, J. Chem. Theory Comput., 2008, 4, 2108-2121.

23 E. C. Beret, R. R. Pappalardo, N. L. Doltsinis, D. Marx and E. Sanchez Marcos, ChemPhysChem., 2008, 9, 237-240.

24 F. Jalilehvand and L. J. Laffin, Inorg. Chem., 2008, 47, 32483254 .

25 L. Kocsis, J. Mink, F. Jaliehvand, L. J. Laffin, O. Berkesi and L. Hajba, J. Raman Spectrosc., 2009, 40, 481-490.

26 A. Stirling, I. Bakó, L. Kocsis, L. Hajba and L. Mink, Int. J. Quantum Chem., 2009, 109, 2591-2598.

27 T. S. Hofer, B. S. Randolf, B. R. Rode and I. Persson, Dalton Trans., 2009, 1512-1515.

28 D. T. Bowron, E. C. Beret, E. Martin-Zamora, A. Soper and E. Sanchez Marcos, J. Am. Chem. Soc., 2012, 134, 962-967.

29 T. Shi and L. I. Elding, Acta Chem. Scand., 1998, 52, 897902, and references therein.

30 B. I. Nabivanets and L. V. Kalabina, Russ. J. Inorg. Chem., 1970, 15, 818-821.

31 Ž. D. Bugarčić, PhD thesis, Svetozar Markovic University, Kragujevac, 1989.
32 N. B. Milić and Ž. D. Bugarčić, Transition Met. Chem., 1984, 9, 173-176.

33 L. Wu, B. E. Schwederski and D. W. Margerum, Inorg. Chem., 1990, 29, 3578-3584.

34 S. A. Wood, Geochim. Cosmochim. Acta, 1991, 55, 17591767.

35 Ž. D. Bugarčić, B. V. Petrović and R. Jelić, Transition Met. Chem., 2001, 26, 668-671.

36 L. R. Kump and R. H. Byrne, Environ. Sci. Technol., 1989, 23, 663-665.

37 C. D. Tait, D. R. Janecky and P. S. Z. Rogers, Geochim. Cosmochim. Acta, 1991, 55, 1253-1264.

38 R. H. Byrne and L. R. Kump, Geochim. Cosmochim. Acta, 1993, 57, 1151-1156.

39 C. D. Tait and D. R. Janecky, Geochim. Cosmochim. Acta, 1993, 57, 1157-1157.

40 S. Yu. Trotskii, A. L. Chuvilin, D. I. Kochubei, B. N. Novgorodov, V. N. Kolomiichuk and V. A. Likholobov, Russ. Chem. Bull., 1995, 44, 1822-1826.

41 R. Faggiani, B. Lippert, C. J. R. Lock and B. Rosenberg, J. Am. Chem. Soc., 1977, 99, 777-778.

42 R. Faggiani, B. Lippert, C. J. R. Lock and B. Rosenberg, Inorg. Chem., 1977, 16, 1192-1196.

43 F. D. Rochon, A. Morneau and R. Melanson, Inorg. Chem., 1988, 27, 10-13.

44 W. J. Moore and L. Pauling, J. Am. Chem. Soc., 1941, 63, 1392-1394.

45 DIFFRAC plus (release 2006) and EVA v. 12.0 rev.o. (Bruker, 2006).

46 A. Thompson, D. Atwood, E. Gullikson, M. Howells, K.-J. Kim, J. Kirz, J. Kortright, I. Lindau, P. Pianatta, A. Robinson, J. Scofield, J. Underwood, D. Vaughan, G. Williams and H. Winick, X-ray Data Booklet, LBNL/ PUB-490 Rev. 2, Lawrence Berkeley National Laboratory, Berkeley, California 94720, 2001.

47 G. N. George and I. J. Pickering, EXAFSPAK - A Suite of Computer Programs for Analysis of X-ray Absorption Spectra, SSRL, Stanford, CA, 1993.

48 H. Mändar, J. Felsche, V. Mikli and T. Vajakas, J. Appl. Crystallogr., 1999, 32, 345-350.

49 G. R. Levi and C. Fontana, Gazz. Chim. Ital., 1926, 56, 388-396.

50 J. R. McBride, G. W. Graham, C. R. Peters and W. H. Weber, J. Appl. Phys., 1991, 69, 1596-1604.

51 J. Waser, H. A. Levy and S. W. Peterson, Acta Crystallogr., 1953, 6, 661-663.

52 O. Glemser and G. Peuschel, Z. Anorg. Allg. Chem., 1955, 281, 44-53.

53 A. G. Christy and S. M. Clark, Phys. Rev. B: Condens. Matter, 1995, 52, 9259-9265.

54 J. Kumar and R. Saxena, J. Less-Common Met., 1989, 147, 59-71.

55 P. Jayaweera, S. Hettiarachchi and H. Ocken, Colloids Surf., A, 1994, 85, 19-27. 